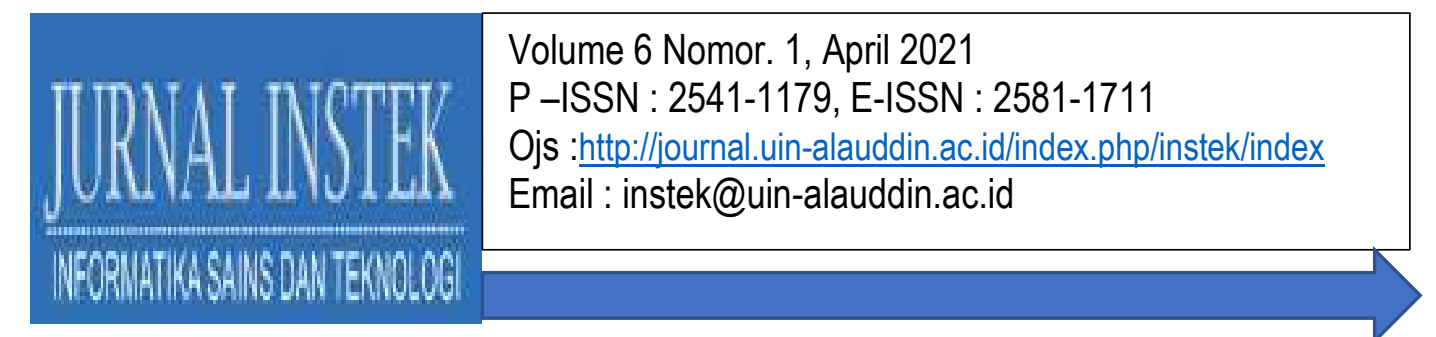

\title{
PENGGUNAAN JARINGAN SENSOR UNTUK MEMONITORING KERETAKAN PADA BANGUNAN BERBASIS INTERNET OF THINGS
}

\author{
MUHAMMAD ASRI ${ }^{1}$, ST. HAISAH ${ }^{2}$, STEPHAN A. HULUKATI ${ }^{3}$ \\ Prodi Teknik Elektro ${ }^{1,3}$, Teknik Arsitektur ${ }^{2}$ \\ Fakultas Teknik Universitas Ichsan Gorontalo ${ }^{1,2,3}$ \\ Email: asriarfah@gmail.com¹, st_haisah@yahoo.com², stephanhulukati17@gmail.com³
}

\begin{abstract}
ABSTRAK
Keretakan pada bangunan sering diakibatkan oleh getaran gempa bumi yang menghasilkan regangan pada bangunan yang menghasilkan kerusakan serius pada bangunan dan bisa membahayakan manusia. Maka dirancanglah sebuah sistem monitoring kerusakan bangunan berkonsep Internet of Things (IoT) dengan menggunakan dua buah perangkat Sensor Getaran (Vibration) yang masing-masing terhubung ke Mikrokontroler Arduino sebagai pengontrol penyalaan LED notifikasi level getaran dan ke NodeMCU sebagai pengirim informasi nilai atau level getaran ke Komputer (ThingSpeak) secara realtime melalui jaringan Internet dan Purwarupa bangunan dengan komposisi bahan sesuai standar sebagai bahan pengujian. Pada pengujian, sistem mengontrol level penyalaan dua warna LED jika nilai getaran yang diterima melebihi nilai tertinggi dari masing-masing warna yang ditentukan, makin tinggi nilai sebuah getaran maka makin tinggi pula regangan yang dihasilkan pada bangunan. Proses monitoring melalui sistem IoT menampilkan visualisasi nilai besaran getaran di Komputer (ThingSpeak).
\end{abstract}

Keywords : Sensor Getaran, Keretakan, Internet of Things

\section{PENDAHULUAN}

Salah satu yang menjadi penyebab keretakan bangunan paling besar dampaknya adalah gempa bumi yang mengakibatkan regangan pada bangunan, retakan yang jika tidak segera ditindaklanjuti akan mengakibatkan kerusakan yang lebih besar pada bangunan. Wilayah Provinsi Gorontalo merupakan daerah rawan bencana termasuk gempa bumi dan berada pada daerah pertemuan dua lempeng besar. Peta Geologi Gorontalo menunjukkan adanya struktur sesar yang memotong wilayah Kota Gorontalo (Nurfitriani dkk., 2014).

Dengan informasi tersebut maka dibuatlah rancangan sistem perangkat yang dapat memantau (memonitoring) retakan bangunan yang diakibatkan oleh regangan 


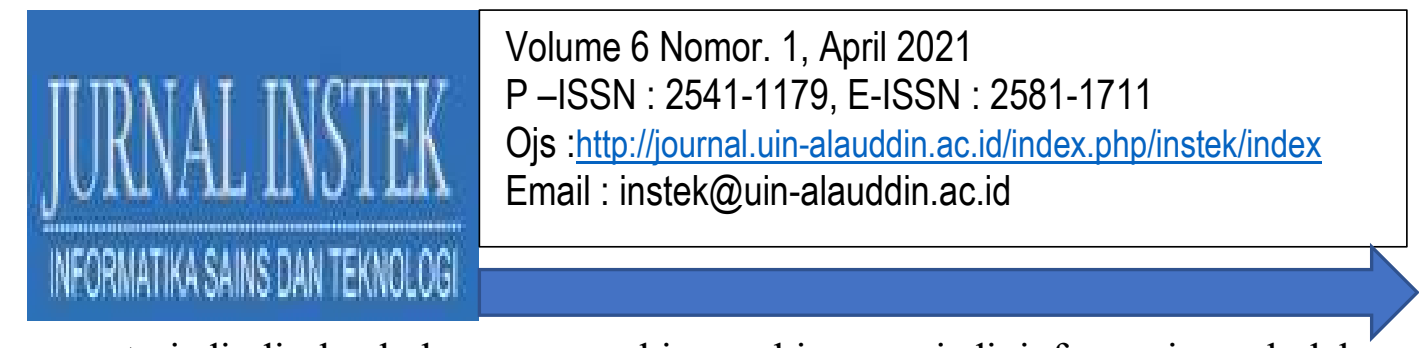

yang terjadi disebuah bangunan sehingga bisa menjadi informasi awal dalam melakukan antisipasi atau perbaikan oleh pengelola bangunan dan rancangan sistem ini pula nantinya dapat memantau kerusakan pada bangunan secara realtime melalui jaringan internet dengan menggunakan perangkat Komputer. Sistem monitoring kerusakan pada bangunan ini sangat penting dilakukan sebagai informasi awal terjadinya kerusakan pada bangunan yang diakibatkan oleh bencana seperti gempa bumi.

Tujuan penelitian ini adalah membangun sebuah sistem monitoring keretakan bangunan berkonsep Internet of Things (IoT) dengan membuat sebuah purwarupa bangunan sebagai obyek pengujiannya. Sistem ini mendeteksi regangan pada bangunan dengan menggunakan sensor getaran yang dikontrol oleh Mikrokontroler Arduino untuk mengolah data level getaran yang menghasilkan indikator nyala LED sebagai indikator kerusakan. Sistem ini juga menggunakan konsep IoT dengan menampilkan visualisasi nilai besaran getaran secara realtime menggunakan jaringan internet yang dapat diakses oleh perangkat Komputer. Sistem monitoring ini diharapkan dapat memberikan kemudahan bagi petugas dalam memelihara bangunan agar mendapatkan informasi awal tentang bahaya kerusakan yang ditimbulkan oleh retakan.

Pada penelitian yang dibuat oleh Saputra, Julio Fajar dkk., meneliti Pembuatan Prototype Sistem Monitoring Getaran Gempa Menggunakan Sensor Module SW-420 (Saputra dkk, 2018), tetapi penelitian belum memasukkan penggunaan Konsep IoT atau Wireless sebagai salah satu outputnya. Sedangkan penelitian Asep Najmurrokhman dkk., yang merancang sistem monitoring kondisi gedung menggunakan konsep wireless sensor network (Najmurrokhman dkk., 2016), jelas tidak menggunakan konsep IoT dengan sensor getaran sebagai indikatornya.

\section{II.METODE PENELITIAN}

\section{A. Perancangan Alat dan Program}

Pada perancangan sistem, hardware dan software yang digunakan meliputi:

1. Mikrokontroler Arduino sebagai pengontrol perangkat; 
Volume 6 Nomor. 1, April 2021

P-ISSN : 2541-1179, E-ISSN : 2581-1711

Ojs :http://journal.uin-alauddin.ac.id/index.php/instek/index

Email : instek@uin-alauddin.ac.id

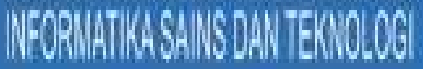

2. Perintah Pemrograman menggunakan sketch Arduino (IDE Arduino);

3. Penggunaan dua sensor getaran (Vibration Sensor) sebagai pendeteksi getaran;

4. LED kuning dan merah sebagai indikator level kerusakan;

5. NodeMCU (ESP8266) sebagai alat pengirim data melalui jaringan WiFi;

6. Baterai (DC Power) 9 VA sebagai sumber tegangan masukan;

7. Purwarupa bangunan batu bata sebagai obyek pengujian kerusakan;

8. PC untuk menampilkan nilai getaran dengan menggunakan ThingSpeak.

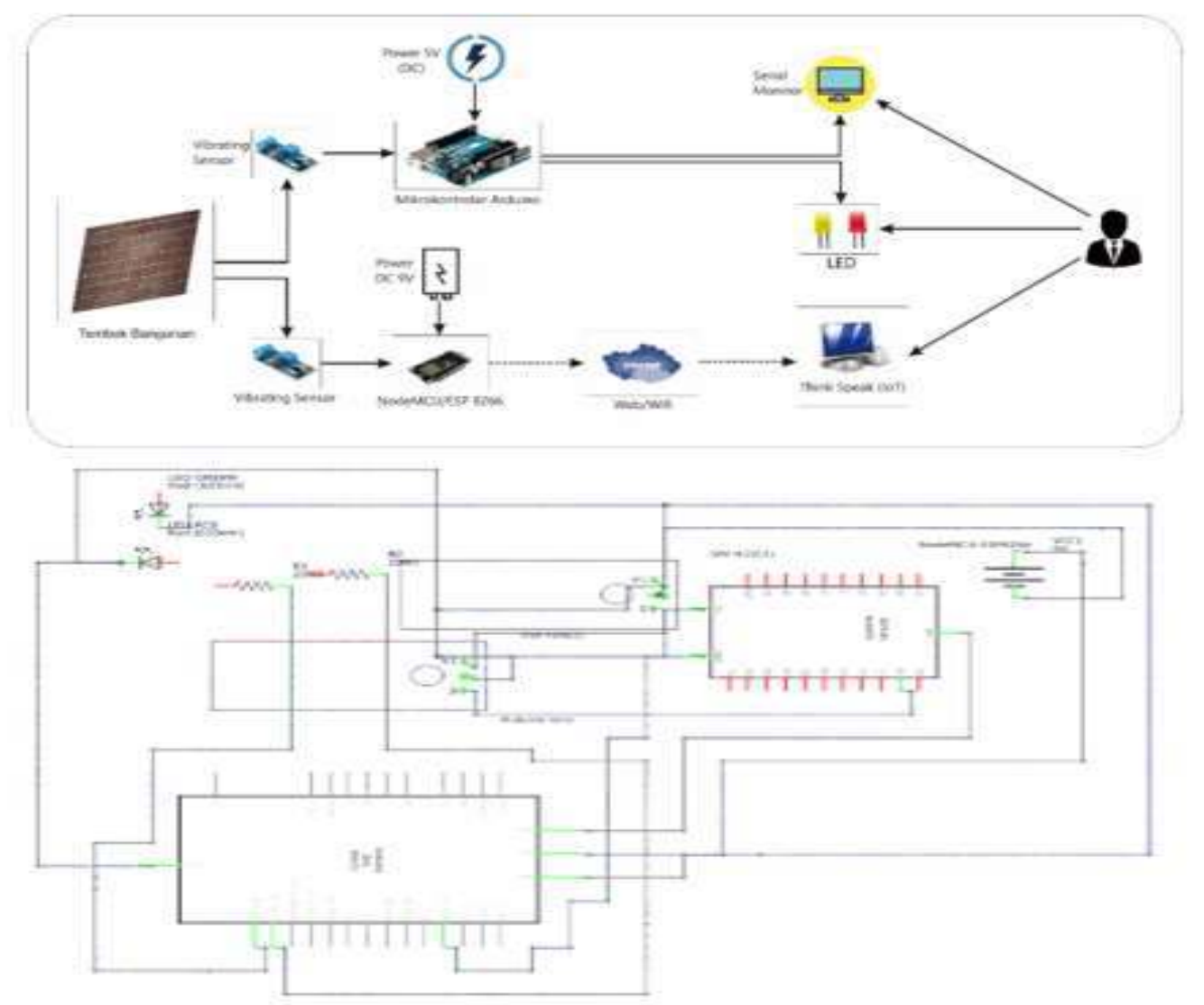

Gambar 1. Perancangan Sistem dan Skema Rangkaian

Rancangan perangkat sistem monitoing keretakan bangunan dan skema rangkaian dapat di lihat pada Gambar 1. Perancangan program pada mikrokontroler Arduino menggunakan bahasa pemrograman IDE Arduino yang digunakan pula di NodeMCU. 


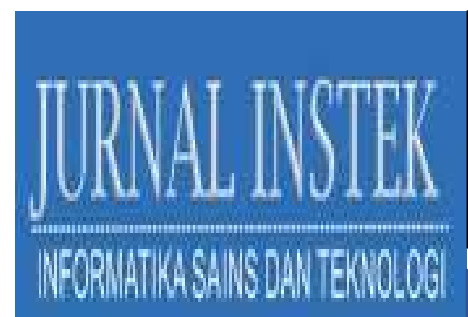

Volume 6 Nomor. 1, April 2021

P-ISSN : 2541-1179, E-ISSN : 2581-1711

Ojs :http://journal.uin-alauddin.ac.id/index.php/instek/index

Email : instek@uin-alauddin.ac.id

\section{B. Penentuan Tingkat Kerusakan}

Dalam penentuan tingkat kerusakan pada bangunan dilakukan pengukuran lebar retakan pada elemen yang mengalami retakan. Semakin besar lebar keretakan yang terjadi maka semakin tinggi tingkat kerusakan yang terjadi (Ariyanto, 2020).

Tabel 1. Penilaian kerusakan bangunan berdasarkan lebar keretakan

\begin{tabular}{|c|l|c|}
\hline $\begin{array}{c}\text { Tingkat } \\
\text { Kerusakan }\end{array}$ & \multicolumn{1}{|c|}{ Kerusakan Secara Tipikal } & $\begin{array}{c}\text { Pendekatan dengan } \\
\text { lebar keretakan (mm) }\end{array}$ \\
\hline 1 & $\begin{array}{l}\text { Retak rambut lebar kurang dari 0,1 mm, bisa } \\
\text { diabaikan. }\end{array}$ & $0-0,1$ \\
\hline 2 & $\begin{array}{l}\text { Retak halus, jarang terlihat pada bagian luar } \\
\text { pasangan bata, Kemungkinan terjadinya } \\
\text { pemisahan atau penyusutan material pada } \\
\text { bangunan. }\end{array}$ & $0,1-1$ \\
\hline 3 & $\begin{array}{l}\text { Retak mudah dimasuki, retak tidak perlu } \\
\text { kelihatan dari luar. }\end{array}$ & $1-5$ \\
\hline 4 & $\begin{array}{l}\text { Pintu dan jendela melekat, kegagalan perbaikan } \\
\text { pada pipa-pipa di dalam tembok. }\end{array}$ & $5-15$ \\
\hline 5 & $\begin{array}{l}\text { Rangka pada jendela dan pintu terdistorsi, lantai } \\
\text { miring, kehilangan beberapa fungsi balok. }\end{array}$ & $15-25$ \\
\hline 6 & $\begin{array}{l}\text { Balok kehilangan kekuatan, dinding miring } \\
\text { sekali. } \\
\text { kerusakan pada jendela dengan distorsi. }\end{array}$ & $>25$ \\
\hline
\end{tabular}

Sumber : Diadopsi dari "Building Research Establisment Digest 251; British Crown Copyright" dalam Buku "Appraising Building Defects", (Cook, G. K., \& Hinks, 1992).

Penentuan tingkat kerusakan ditentukan dengan menggunakan nilai angka yang dimulai dengan nilai 1 sebagai tanda tingkat kerusakan yang paling ringan, dan 6 sebagai nilai yang terbesar, yang menunjukkan bahwa kerusakan yang terjadi pada bangunan sudah mengalami tingkat yang serius dan memerlukan perawatan yang kompleks (Nuswantoro \& Raya, 2018). Secara rinci dan tingkat kerusakan yang terjadi pada bangunan gedung dikategorikan seperti pada Tabel 1.

Dengan mengacu pada hasil survey lokasi bangunan yang mengalami keretakan maka dapat dilakukan penilaian kerusakan/keretakan bangunan yang telah dibahas pada Tabel 1 yaitu dengan mencari atau mendapatkan data primer dan data sekunder, dalam hal ini peneliti telah menyederhanakan penilaian tersebut menjadi tiga kategori level kerusakan agar nantinya implementasi pada perangkat lebih mudah dipahami oleh operator (lihat Tabel 2): 


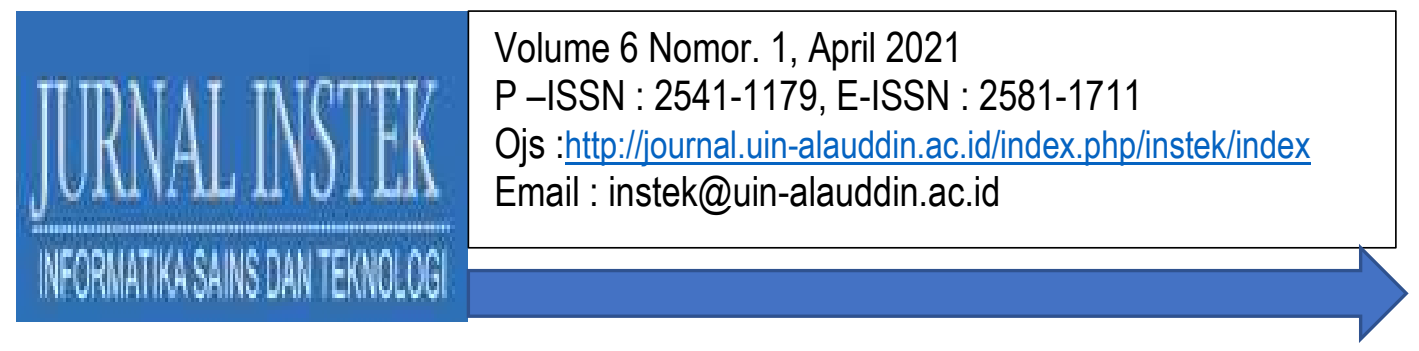

Tabel 2. Level Kerusakan Bangunan

\begin{tabular}{|l|c|c|c|}
\hline \multicolumn{1}{|c|}{ Level Kerusakan } & $\begin{array}{c}\text { Ukuran Keretakan } \\
(\mathbf{m m})\end{array}$ & Indikator LED & $\begin{array}{c}\text { Indikator IoT } \\
\text { (ThingSpeak) }\end{array}$ \\
\hline Rendah & $1-2$ & - & - \\
\hline Sedang (Waspada/Siaga) & $3-4$ & Kuning & - \\
\hline Tinggi/Berat (Bahaya) & $>=5$ & Merah & Merah \\
\hline
\end{tabular}

\section{C.Tahapan Penelitian}

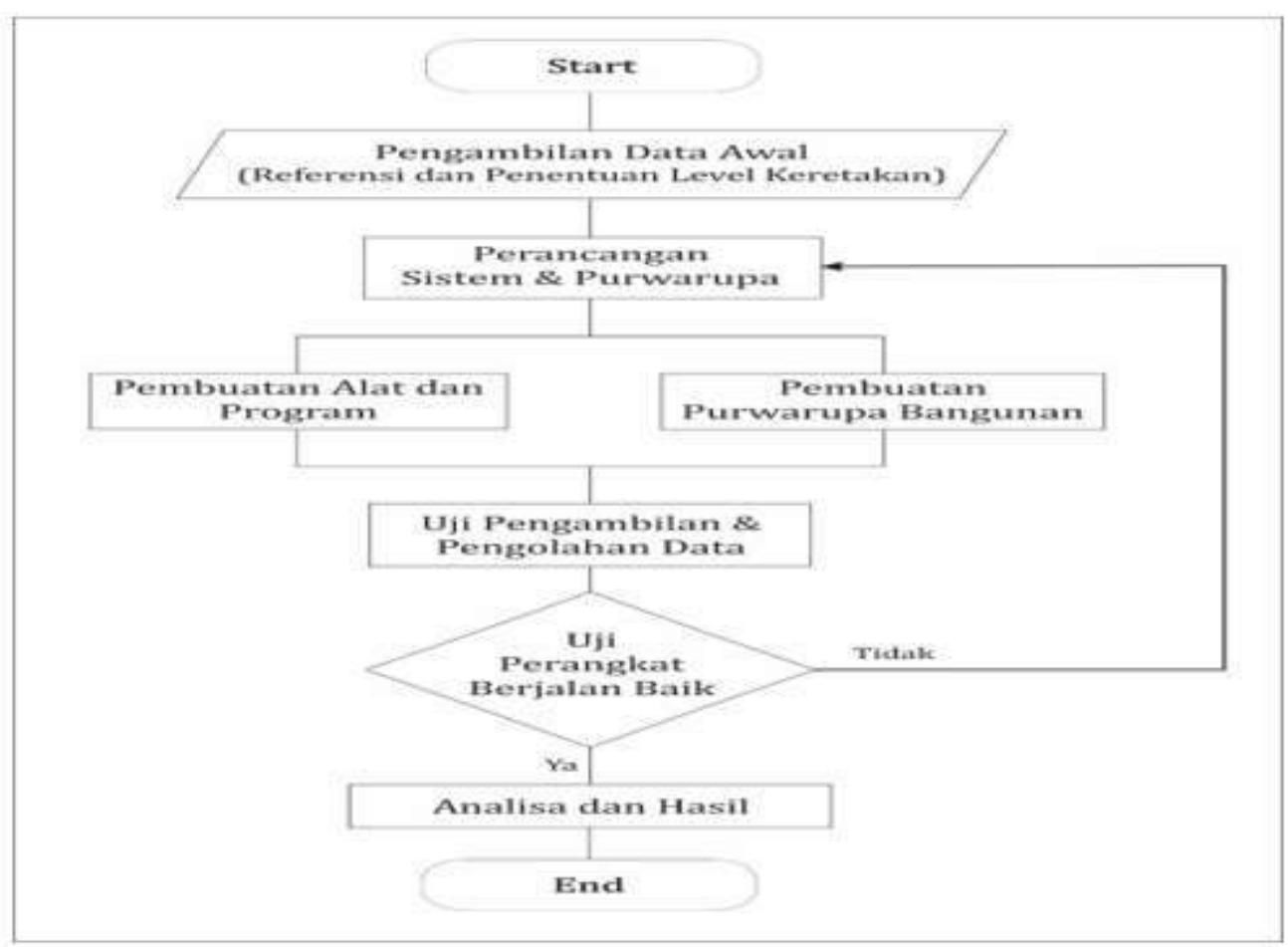

Gambar 2. Flowchart Alur Penelitian

Langkah-langkah penelitian yang akan dilakukan seperti pada alur penelitian pada Gambar 2 dengan penjelasan sebagai berikut:

1. Tahap awal dengan mengambil data pada tempat yang kondisi bangunannya memiliki keretakan sebagai acuan menentukan level keretakan bangunan;

2. Tahap kedua merancang dan membuat bangunan purwarupa sebagai obyek pengujian berbentuk tembok persegi empat yang terbuat dari struktur susunan batu bata yang disesuaikan dengan standar komposisi bahan bangunan. Kemudian merancang dan membuat dua buah sistem monitoring yang masing-masing menggunakan sebuah sensor getaran yang diletakkan sejajar dipermukaan 
Volume 6 Nomor. 1, April 2021

P-ISSN : 2541-1179, E-ISSN : 2581-1711

Ojs :http://journal.uin-alauddin.ac.id/index.php/instek/index

Email : instek@uin-alauddin.ac.id

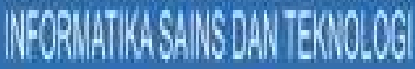

purwarupa tembok bangunan yang akan diuji. Pada sistem pertama perangkat dapat mendeteksi perubahan nilai getaran pada bangunan menggunakan mikrokontroler Arduino yang telah terprogram (Gambar 3), untuk mengindikasikan level keretakan bangunan pada nyala lampu LED. Pada sistem kedua perangkat menggunakan NodeMCU yang memberikan informasi nilai getaran berupa tampilan visual secara realtime ke Komputer menggunakan jaringan internet;

3. Tahap pengujian, pengambilan dan pengolahan data dilakukan dengan menguji kinerja ke dua sistem dengan waktu yang telah ditentukan meliputi Proses pekerjaan awal dengan memberikan tekanan kepada dinding bangunan purwarupa hingga terjadi regangan dan menghasilkan retakan. Kemudian nilai getaran yang didapat diproses oleh Arduino untuk menentukan level kerusakan melalui indikasi nyala LED. Sedangkan data nilai getaran yang diolah oleh NodeMCU dikirimkan menggunakan konsep IoT dan diterima oleh perangkat Komputer berupa tampilan visual data/ nilai getaran.

4. Analisa dan Hasil : pada tahapan ini akan dianalisa kinerja perangkat monitoring setelah diuji, sampai dimana tingkat keretakannya dan akan diputuskan tindakan yang harus diambil, jika terjadi masalah saat perangkat diuji maka sistem secara otomatis akan dikembalikan ke poin 2 .

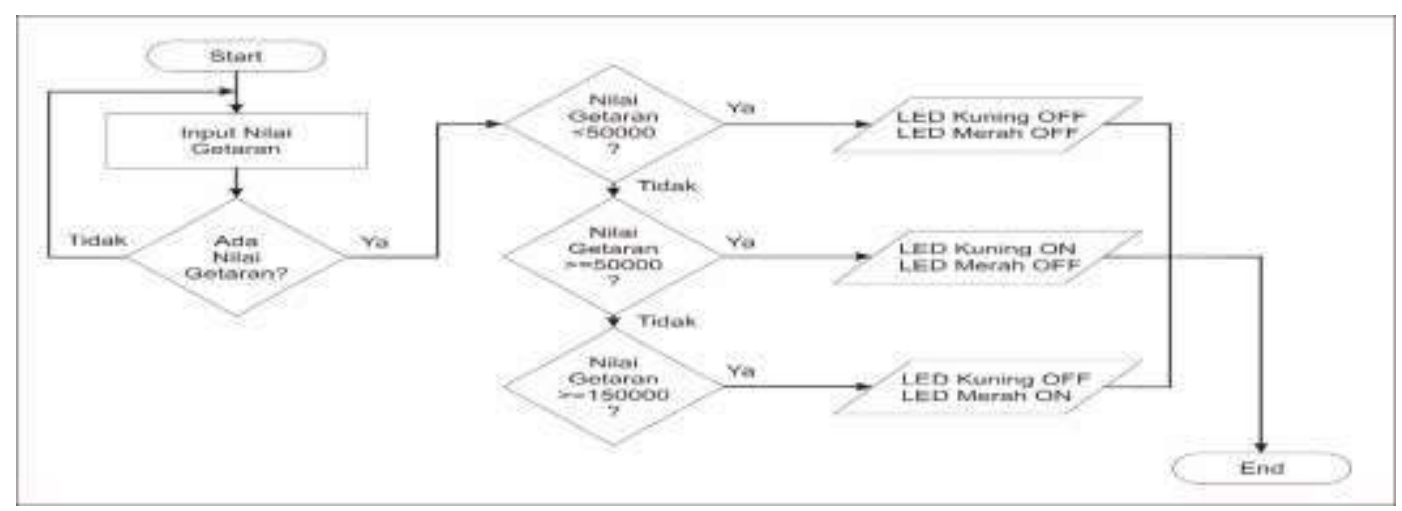

Gambar 3. Flowchart Alur Program 


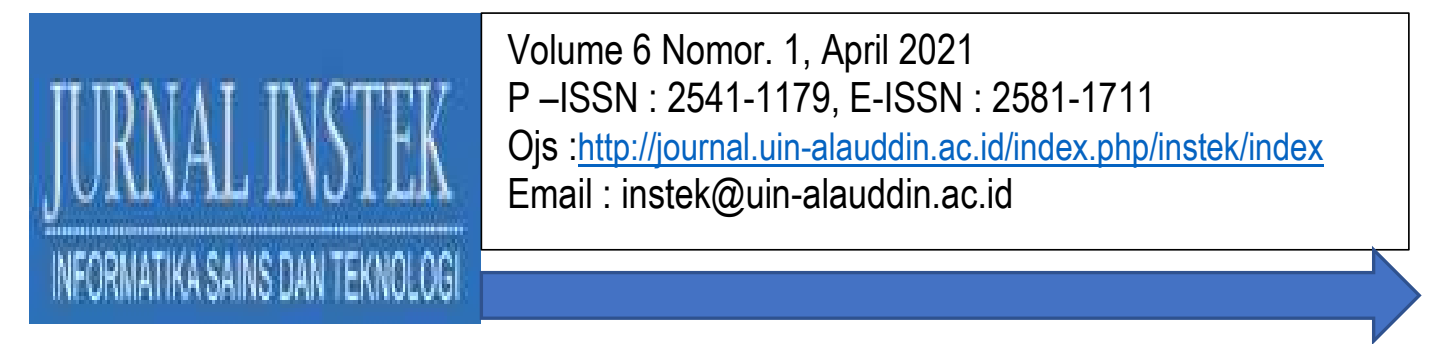

\section{III.HASIL DAN PEMBAHASAN}

\section{A. Proses Pengujian}

Pada proses pengujian sistem monitoring ini kedua perangkat sistem dipasang pada purwarupa bangunan ditempat yang ditentukan, dimana kedua sensor getaran diletakkan secara vertikal di dinding bangunan purwarupa tersebut agar getaran yang dihasilkan tidak terlalu jauh perbedaan nilainya (lihat Gambar 4). berjalan dengan baik dengan hasil pembacaan nilai getaran pada serial monitor dan indikasi nyala lampu LED (lihat Tabel 2) dan diuji dalam waktu 120 detik (2 menit) secara bersamaan ini dimaksudkan agar hasil nilai getaran yang terbaca dari kedua sensor sebanding sehingga kesalahan pembacaan kedua sensor bisa dikoreksi.

Pengujian getaran terhadap bangunan purwarupa disimulasikan sebagai gempa dengan membuat getaran hingga terjadi regangan yang menghasilkan nilai getaran dan level keretakan pada bangunan yakni dengan menggunakan martil dan tangan (manual) sebagai bentuk tekanan dan guncangan yang kuat pada purwarupa bangunan.

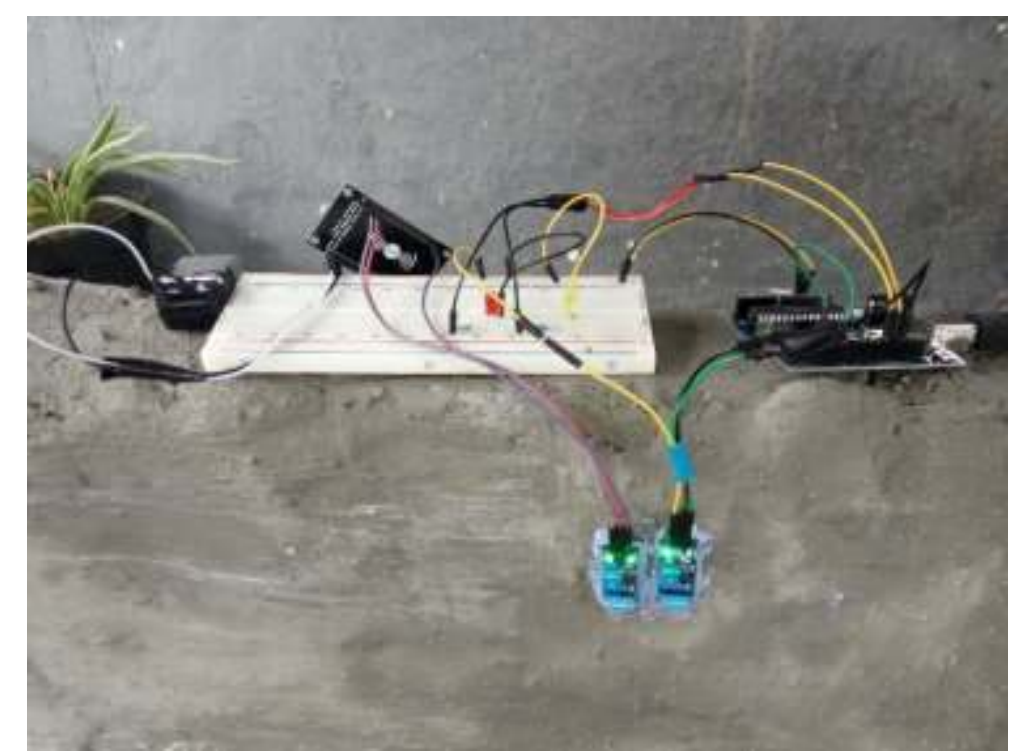

Gambar 4. Pemasangan Perangkat Monitoring Keretakan Bangunan

\section{B. Hasil Pengujian}

Adapun hasil dari pengujian atau pengukuran besaran nilai getaran pada perangkat monitoring keretakan bangunan ini dapat di lihat pada Tabel 3. Untuk mendapatkan level kerusakan yang terjadi, seluruh data dikumpulkan dan diurut 


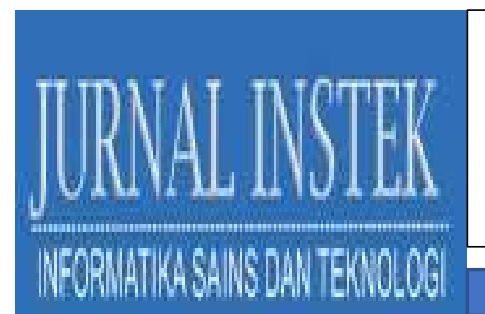

Volume 6 Nomor. 1, April 2021

P-ISSN : 2541-1179, E-ISSN : 2581-1711

Ojs :http://journal.uin-alauddin.ac.id/index.php/instek/index

Email : instek@uin-alauddin.ac.id

dari kerusakan bagian atas hingga ke bagian bawah bangunan dan masih di permukaan tanah (Gambar 5). Data kerusakan yang terkumpul kemudian dianalisa tingkatan atau level kerusakan bangunan tersebut. Untuk mendapatkan suatu format instrument penilaian kerusakan yaitu dengan membuat suatu standar atau sistem penilaian berupa level kerusakan pada bangunan terutama volume ukuran dimensi keretakan yang ditetapkan pada objek bangunan dengan nilai tingkat kerusakan/keretakan mulai dari 0 sampai lebih dari $5 \mathrm{~mm}$.

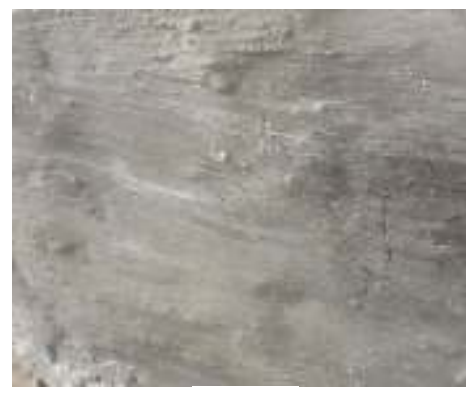

(a)

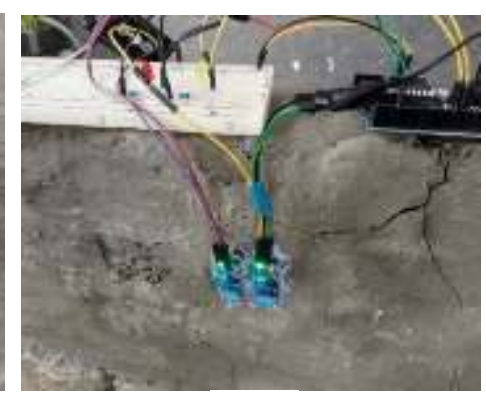

(b)

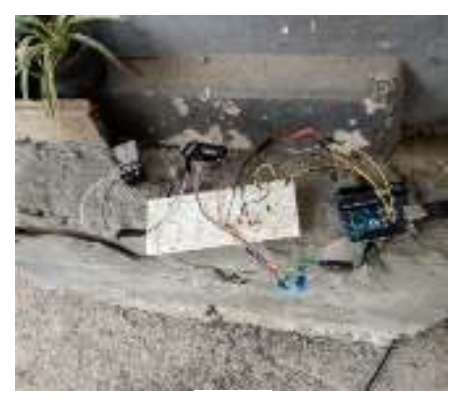

(c)

Gambar 5. Simulasi Kategori Level Dimensi Keretakan Bangunan, (a) Rendah, (b) Sedang, (c) Berat.

Tabel 3. Hasil Pengujian Nilai Getaran

\begin{tabular}{|c|c|c|c|c|c|c|c|}
\hline \multirow{2}{*}{$\begin{array}{c}\text { Waktu } \\
\text { (detik) }\end{array}$} & $\begin{array}{c}\text { Nilai Serial } \\
\text { Monitor }\end{array}$ & $\begin{array}{c}\text { LED } \\
\text { Kuning }\end{array}$ & $\begin{array}{c}\text { LED } \\
\text { Merah }\end{array}$ & $\begin{array}{c}\text { Level } \\
\text { Kerusakan } \\
\text { Bangunan }\end{array}$ & $\begin{array}{c}\text { Nilai } \\
\text { Getaran } \\
\text { (detik) }\end{array}$ & $\begin{array}{c}\text { Indikator } \\
\text { Getaran }\end{array}$ & $\begin{array}{c}\text { Level } \\
\text { Kerusakan } \\
\text { Bangunan }\end{array}$ \\
\hline 0 & 0 & - & - & - & 0 & - & - \\
\hline 15 & 130421 & Nyala & - & Rendah & 125912 & - & Rendah \\
\hline 30 & 22670 & - & - & Rendah & 20236 & - & Rendah \\
\hline 45 & 108666 & Nyala & - & Sedang & 101730 & - & Sedang \\
\hline 60 & 224201 & - & Nyala & Berat & 212861 & Nyala & Berat \\
\hline 75 & 192235 & - & Nyala & Berat & 181294 & Nyala & Berat \\
\hline 90 & 67902 & Nyala & - & - & 62034 & - & - \\
\hline 105 & 20768 & - & - & - & 18076 & - & - \\
\hline 120 & 11092 & - & - & - & 9012 & - & - \\
\hline \multicolumn{7}{|c|}{ Untuk pengujian konsep Internet of Things (IoT) peneliti menghubungkan } \\
\hline
\end{tabular}

perangkat NodeMCU yang didalamnya telah terintegrasi modul ESP8266 yang digunakan untuk akses internet (WiFi) sehingga perangkat lain bisa terhubung secara tanpa kabel (wireless) sehingga pengguna dapat melihat secara langsung dengan menggunakan PC/Komputer data getaran, level dan indikasi keretakan 


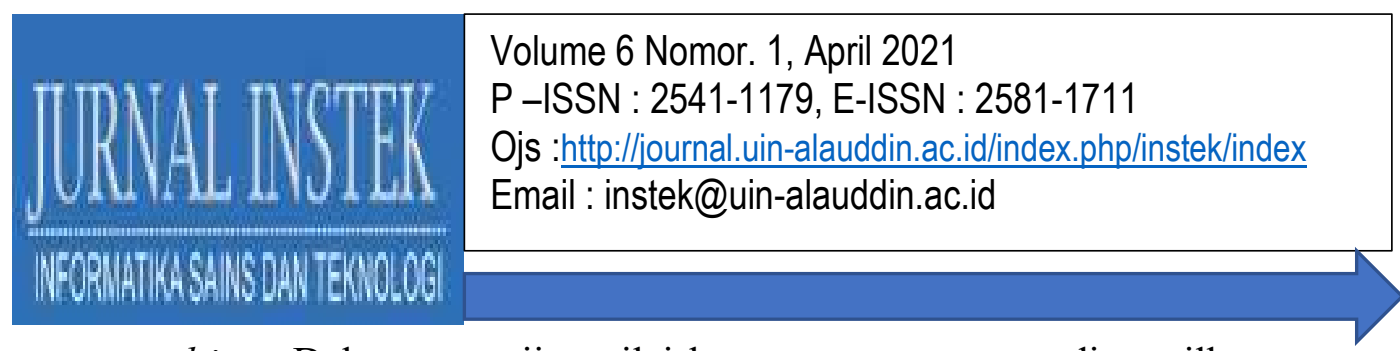

secara realtime. Dalam pengujian nilai besaran getaran yang ditampilkan secara wireless menggunakan software ThingSpeak yang tampil di PC/komputer. Adapun contoh tampilan pengujian hasil pembacaan sensor getaran melalui konsep IoT dapat dilihat di Gambar 6.
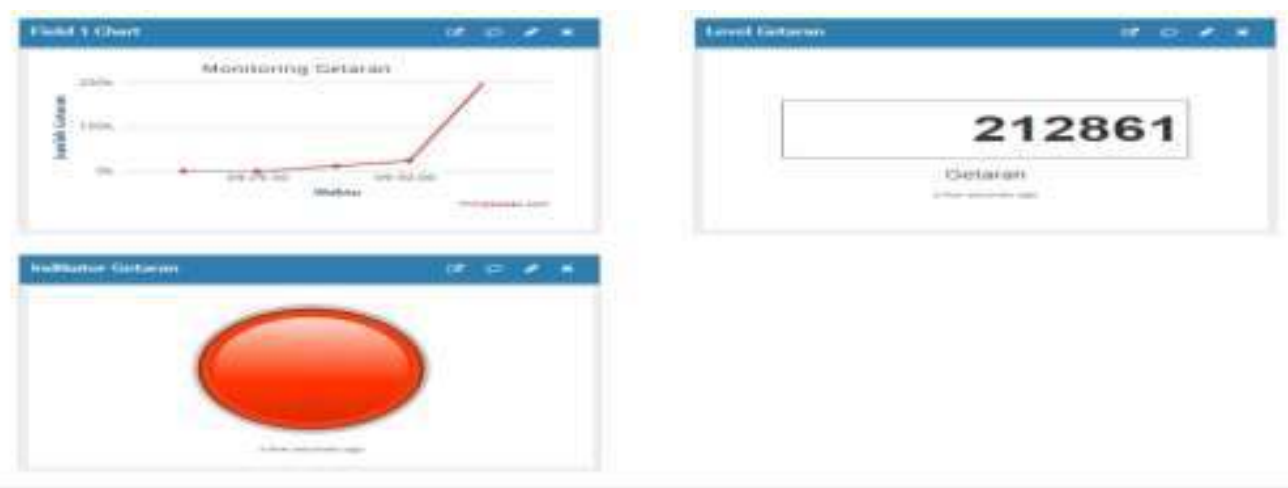

Gambar 6. Tampilan Hasil Nilai Getaran Pada Sistem IoT (ThingSpeak).

\section{C.PEMBAHASAN}

Dari hasil pengujian kedua sistem tersebut didapatkan jika diberikan tekanan dan getaran dari tingkatan rendah ke tinggi (uji simulasi pemberian tekanan dan getaran secara manual tidak dilakukan secara konstan) maka dapat mengubah tingkatan atau level dimensi keretakan pada bangunan, dimana jika diberikan pengujian getaran di bawah 50000 pada pembacaan sensor maka lebar dimensi keretakan sekitar 1-2 mm, jika getaran yang diberikan dinaikkan menjadi lebih besar lebih atau sama dengan 50000 maka tingkatan dimensi keretakan menjadi Sedang sekitar $2-4 \mathrm{~mm}$, dan jika getaran yang diberikan dinaikkan lagi lebih dari 150000 maka tingkatan dimensi keretakan menjadi tinggi/besar. Perbedaan output pembacaan nilai getaran sensor kedua sistem tersebut rata-rata 7\% ini disebabkan perbedaan pembacaan sensor saat diberi getaran. Analisis nilai besaran getaran dan level kerusakan bangunan dapat dilihat pada Tabel 4 dan Gambar 6 .

Tabel 4. Analisis Nilai Besaran Getaran dan Tingkatan Kerusakan Bangunan

\begin{tabular}{|c|c|c|c|}
\hline No & $\begin{array}{c}\text { Besaran Getaran/Tekanan Yang } \\
\text { Diberikan }\end{array}$ & Dimensi Keretakan Bangunan & Indikator \\
\hline 1 & $<50000$ & $1,2-1,8 \mathrm{~mm}($ Rendah $)$ & - \\
\hline 2 & $>=50000 \mathrm{~s} / \mathrm{d}<150000$ & $2,2-3,1 \mathrm{~mm}$ (Sedang) & Kuning \\
\hline
\end{tabular}




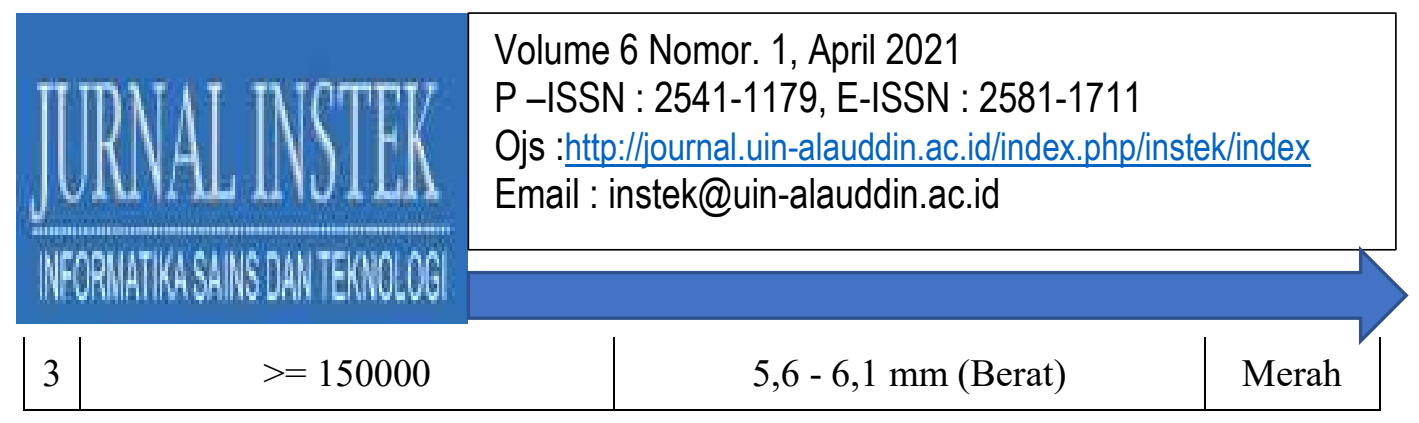

\section{IV.KESIMPULAN}

Dari rangkaian hasil penelitian mulai dari pengumpulan data hingga hasil pengujian dapat disimpulkan bahwa makin tinggi besaran nilai getaran maka semakin besar tingkat terjadinya kerusakan pada bangunan. Dengan demikian pada pengujian sistem monitoing berkonsep IoT ini sistem dapat menampilkan nilai besaran getaran pada bangunan sesuai level yang dirancang sebelumnya sehingga diharapkan nantinya para operator bangunan dapat mendapatkan informasi keadaan bangunan secara detail berupa visualisasi nilai besaran getaran dan indikator kerusakan secara realtime pada Komputer melalui jaringan internet.

\section{DAFTAR PUSTAKA}

Ariyanto, A. S. (2020). Analisis Jenis Kerusakan Pada Bangunan Gedung Bertingkat ( Studi Kasus pada Gedung Apartemen dan Hotel Candiland Semarang ). Bangun Rekaprima, 06(01), 45-57.

Cook, G. K., \& Hinks, D. A. J. (1992). Appraising Building Defects: Perspectives on Stability and Hygrothermal Performance. United Kingdom: Longman Scientific and Technical.

Najmurrokhman, A., Wibowo, B. H., \& Abdillah, A. (2016). Perancangan Sistem Monitoring Kondisi Gedung Menggunakan Konsep Wireless Sensor Network. Seminar Nasional Teknologi Dan Sains (SNTS) II, 23-24. https://doi.org/10.31227/osf.io/apnm4

Nurfitriani, Pasau, G., \& Raharjo, S. S. (2014). Identifikasi Sesar di Wilayah Gorontalo dengan Analisis Mekanisme Bola Fokus. Jurnal MIPA, 3(1), 40. https://doi.org/10.35799/jm.3.1.2014.3905

Nuswantoro, W., \& Raya, U. P. (2018). Artikel Jurnal ANALISIS JENIS KERUSAKAN PADA BANGUNAN PERUMAHAN oleh Waluyo Nuswantoro. Jurnal Teknik Industri Terintegrasi (JUTIN), 1(2), 58-68.

Saputra, J. F., Rosmiati, M., \& Sari, M. I. (2018). Pembangunan Prototype Sistem Monitoring Getaran Gempa Menggunakan Sensor Module SW-420. EProceeding of Applied Science, 4(3), 2055-2068. 